\title{
Integrating remote sensing, geographic information systems and global positioning system techniques with hydrological modeling
}

\author{
Jay Krishna Thakur ${ }^{1} \cdot$ Sudhir Kumar Singh ${ }^{2} \cdot$ Vicky Shettigondahalli Ekanthalu $^{3}$
}

Received: 3 May 2015/Accepted: 19 January 2016/Published online: 21 March 2016

(C) The Author(s) 2016. This article is published with open access at Springerlink.com

\begin{abstract}
Integration of remote sensing (RS), geographic information systems (GIS) and global positioning system (GPS) are emerging research areas in the field of groundwater hydrology, resource management, environmental monitoring and during emergency response. Recent advancements in the fields of RS, GIS, GPS and higher level of computation will help in providing and handling a range of data simultaneously in a time- and cost-efficient manner. This review paper deals with hydrological modeling, uses of remote sensing and GIS in hydrological modeling, models of integrations and their need and in last the conclusion. After dealing with these issues conceptually and technically, we can develop better methods and novel approaches to handle large data sets and in a better way to communicate information related with rapidly decreasing societal resources, i.e. groundwater.
\end{abstract}

Keywords Hydrological modeling · Groundwater . Remote sensing · GIS · GPS

Jay Krishna Thakur

jay@thakur.co

Sudhir Kumar Singh

sudhirinjnu@gmail.com

Vicky Shettigondahalli Ekanthalu

vicky.se1411@gmail.com

1 Environment and Information Technology Centre-UIZ, Neue Grünstrasse 38, 10179 Berlin, Germany

2 K. Banerjee Centre of Atmospheric and Ocean Studies, IIDS, Nehru Science Centre, University of Allahabad, Allahabad-211002, UP, India

3 Environmental and Resource Management Studies, Brandenburg Technical University, 03046 Cottbus, Germany

\section{Introduction}

The integration of remote sensing (RS), geographic information systems (GIS) and global positioning system (GPS) (3S) has received considerable attention in the field of groundwater hydrology in recent times. Groundwater is a subterranean natural resource, having multidimensional facets. The popular technique i.e. remote sensing from different platforms (e.g. aircraft, satellite and others) has become a valuable tool for developing better understanding of subsurface water conditions (Todd 1980; Barrett and Kidd 1987). Remote sensing includes geophysical surveys of gravity, magnetics and electromagnetics (Brunner et al. 2006). Only the geophysical survey offers the possibility of exploring underneath information (Brunner et al. 2006). Remote sensing technique has advantage over traditional/conventional techniques in terms of spatial, spectral, radiometric and temporal data availability. It offers acquisition of real- or near-real-time data from inaccessible or remote areas within very short span of time. Therefore, it is an efficient and powerful technique in assessment, exploration, evaluation, analysis, monitoring and management of groundwater for the long-term societal benefits. Remote sensing is a rapidly changing domain with the advent of new improved sensors, platforms and application techniques which supports new forms of data and newer views of the landscapes through which hydrologist/hydraulic engineer could better evaluate the earth's surface and other specific features (Running et al. 1994). Satellite data provide quick and useful baseline information about the parameters and/or variables controlling the occurrence and movement of groundwater, such as macro and micro topography, geology, lithology, stratigraphy, structural controls (palaeo and neo-tectonics), geomorphology, soil types, land use/cover and geological lineaments (Das 
1994). With the advent of new fine spatial (hyper spatial) and hyperspectral resolution satellite and aircraft imagery, new applications for large-scale mapping and monitoring have become possible with fine details (Fortin and Bernier 1991). In arid and semi-arid environment, the major and minor geological feature can easily be interpreted because of very little vegetative and other category of land use/cover to hide the structural and stratigraphic information. Vegetation shows close association with geology (Engman and Gurney 1991), which offers both indirect and direct ways for quantitative and qualitative valuable information about groundwater. The vegetative parameter and variables extracted from remotely sensed images help in the identification of subsurface manifest. Wilkinson (1996) summarized the major challenges and problems to overcome for effectual use of the new form of satellite data. Gahegan and Flack (1999) presented a way to use modern computing tools with these data and different GIS data themes to resolve some of the identified problems. In the early 1960-70s, mostly hydrologists and hydrogeologists achieved the higher success rates when sites for drilling or detailed geophysical surveys were guided by lineament mapping (Teeuw 1995), based on both aerial photography (Sharpe and Parizek 1979) and remotely sensed images (Teme and Oni 1991). Various researches and studies have demonstrated the potentiality of satellite remote sensing in groundwater mapping, exploration and management. GIS has ability to store, arrange, retrieve, classify, manipulate, analyze and present huge spatial data and information in intelligible way (Howari et al. 2007). GIS offers a common ground upon which people, pixel and their data could easily interact (Lakhtakia et al. 1993). In current scenario, GIS is regarded as essential and efficient technique for studies especially for extended and complex groundwater systems. The utilities and potentialities of GIS in hydrogeology and hydrologic modeling are only at its beginning, but many successful applications have already started to develop (Bhasker et al. 1992; Gossel et al. 2004) and GIS has more scope in groundwater hydrologic modeling to develop better plans and pragmatic policy. There are few very good reviews on remote sensing and GIS applications in groundwater hydrology (Engman and Gurney 1991). These reviews highlighted the crucial role of remote sensing applications in groundwater hydrology. Out of these reviews, one excellent review was done by (Jha et al. 2006) entitled "Integrated Remote Sensing and Geographic Information Systems: Prospects and Constraints" which highlighted Remote Sensing and GIS technologies utilities in groundwater hydrology. The paper revealed six major areas of Remote Sensing and GIS applications in groundwater hydrology (1) exploration and assessment (2) selection of artificial recharge sites (3) GIS based sub-surface flow and pollution modeling (4) groundwater pollution hazard assessment and protection planning (5) estimation of natural recharge distribution (6) hydrological data analysis and process monitoring. The paper also dealt with the constraints of remote sensing and GIS applications in developing nation.

Sander et al. (1996) demonstrated the combined use of various remotely sensed images acquired from different sensors such as Landsat TM, SPOT and infrared aerial photographs along with GPS, for improving spatial accuracy and reduction in redundancy, as well as used GIS as an interoperable platform for integrating various multi-source data to develop well sitting strategies with improved spatial accuracy and minimized cost. Travaglia and Dainelli (2003) had applied an integrated approach including remote sensing, GIS and field data. The result of their study indicated groundwater movement along fault. Local and regional flow of groundwater can also be detected with the help of remotely sensed images (especially thermal imagery) and simple to complex, i.e. one dimensional (1D), two dimensional (2D) and three dimensional (3D) hydrologic modeling of local and regional groundwater flow can be performed through GIS. GIS has capability of geo-visualization for improved understanding. Various researches and studies have shown the positive influence of space tool and techniques in targeting the artificial recharge. When natural recharge from rainfall events cannot meet continuous increasing groundwater demands, the balance is disrupted which calls for need of artificial recharge on local and regional basis (Shultz 1994). To understand the nature of aquifer system, many researchers are now using digital techniques to derive geological, structural and geomorphologic details (Humes et al. 1994). This is necessary in order to estimate and target the regional artificial recharge sites for recharging in order to balance withdrawal and recharge. The rapid delivery of spatial data can be coupled with GPS and current field computer technologies to bring the imagery into the field for cover type validation. Global positioning system (GPS) technology renders an excellent basis for $x, y, z$ location measurements (Case 1989; Lunetta et al. 1991).

Global positioning system (GPS) technology greatly enhances the ease and versatility of spatial data acquisition and also diversifies the approaches with which it is integrated with remote sensing and geographic information system (Gao 2002).

\section{Hydrological modeling}

In general, there are two idealized uses for the simulation in groundwater hydrology. The first is the prediction (or forecasting) of future events based on validated and calibrated model (Loague and Freeze 1985). The second object 
is to develop the conceptual methods for the designing of future experiments to improve the understanding of the process (Loague 1988). Remote sensing methods are the most assuring source of spatially distributed data for both calibration and model input parameters. Topography, channel positions, aquifer thickness, evapotranspiration and precipitation data are all based on remote sensing (Milzow et al. 2008). Numerous lumped-parameter models (e.g. HEC-1, HEC-2, MODFLOW, SHE and SWAT) have been linked to GIS in these ways to predict surface and groundwater flows. Orzol and McGrath (1992), for example, described how the structure of MODFLOW was altered to promote its integration with ArcInfo. They demonstrated that the results were the similar as if the model was run as a stand-alone product. Likewise, Maidment and Hellweger (1999) automated a procedure to illustrate and connect hydrologic elements in ArcInfo and ArcView and drafted the results to an ASCII file that is readable by the Hydrologic Engineering Center's-Hydrologic Modeling System (HEC-HMS). These lumped models simulate broad spectrum of processes (e.g. surface and subsurface water flow, sediment and pollutants transport) with continuous time simulation (e.g. SWAT-Arnold et al. 1993). These watershed-based models have been connected to GIS for many years and at present, several online versions are at hand (e.g. SWAT- Srinivasan and Arnold 1994 and L-THIA 2- Lim et al. 1999). The methods used to hookup GIS and simulation models also vary extremely from one application to another (Wilson and Gallant 2000). Watkins et al. (1996) compared the advantages and disadvantages of various GIS/Model interfaces and showed how the spatial analysis and visualization potential of GIS could be used to enhance parameter estimation/determination, scale effects, grid design, access the responsiveness of model outputs to parameter uncertainty and model discretization.

\section{Uses of remote sensing in hydrological modeling}

There are numerous forms of remote sensing among which the most familiar type is the satellite remote sensing which as cost effective application comparison to geophysical survey but, it requires ground-truthing for validation of the results to meet the proper standard. Hence, groundwater models need spatio-temporal distribution of input and calibration of data (Brunner et al. 2007a, b). If such data is available, then the models play integral role in improved decision-making and minimize the chance of uncertainties. The pertaining entities such as water flux, transmissivity or head cannot be observed directly by optical remote sensing. Becker (2006) did the extensive review on the potential of satellite remote sensing for groundwater, the ability of remote sensing to measure groundwater potential, storage and fluxes.

\section{Optical remote sensing in groundwater hydrology}

Remote sensing can expose the information that is not observable at ground in remote areas (Blumberg 1998; Dabbagh et al. 1997). Optical remote sensing has no or very limited ground penetrating capabilities ranging from upper few centimeters to very few meters inside the earth surface because it consists of visible and thermal domain. The optical remote sensing lies between the bands ranging from 0.4 to $12.45 \mu \mathrm{m}$, which behaves differently when it is interacted with different matters in different conditions. Visible domain (VD) offers information regarding state and flux variables for selecting groundwater recharge sites, water quality, simulation of groundwater systems and other variables and parameters. Thermal domain (TD) deals with land surface temperature which offers valuable information in terms of thermal aberrations that can easily be detected in thermal infrared remotely sensed data. Thermal data (near infrared) can also give information on potential groundwater recharge sites, parameters for simulation of groundwater systems, water quality, etc.

Satellite remote sensing data are available from Landsat multi spectral scanner (MSS) with $80 \mathrm{~m}$ spatial resolution in early 1972. Before 1972, single broad spectrum aerial photographs were used for mapping of hydrogeological units and geomorphological features. Smith (1997) discovered that MSS band $7(0.8-1.1 \mu \mathrm{m})$ was precisely suitable for distinguishing water or moist soil from dry surface due to strong absorption of water near infrared band.

Kaufman et al. (1986) manifested the potential application of high resolution (Landsat TM) data with the combination of TM bands 1, 4 and 7 to identify different lithological units based on textured properties and vegetation densities. They also reported main flow paths and submarine springs near the coast with the aid of TM thermal band 6. Teeuw (1995) used Landsat Thematic Mapper (TM) to examine groundwater exploration sites in the region of fine-grained sediments west of Tamale in northern Ghana and to locate fracture zone with the help of Landsat TM. They used the simple contrast enhanced (histogram- stretched) for images of band 4 (Near InfraRed, $\quad 0.76-0.90 \mu \mathrm{m}$ ), band 5 (Mid InfraRed, 1.55-1.75 $\mu \mathrm{m}$ ), and band 6 (Thermal InfraRed, 10.4-12.45 $\mu \mathrm{m})$, to produce appropriate images. Band 4 can be used in best way to distinguish different types of vegetation and soil, band 5 provides information about shallow depressions, valleys and other associated features and band 6 records thermal anomalies of the earth's surface, which is useful for identifying major lineaments. The 
lineaments are the potential sites for artificial recharge and exploration. Travaglia and Dainelli (2003) used Landsat enhanced thematic mapper (ETM) data in digital format due to the availability of three near to mid infrared bands, extremely useful for the terrain and lineament mapping and analysis. Additionally as Landsat ETM provided eight coregistered spectral channels, this permitted large spectrum of band combinations which are useful in visual interpretation of different features. In the view of the hydrological objectives, Landsat ETM data were selected as acquired in the dry season to verify features (vegetation, soil moisture) related to the occurrence of water and to avoid overshadowing by too much vegetation. Drainage, which is conveniently visible in remote sensing imagery, thus it reflects the lithology and structure of a given area to varying degrees and can be of higher value for groundwater resources evaluation (Singh et al. 2013).

Tensional faults, that is those orthogonal to the direction of crustal extension or parallel to the direction of the tectonic stress, may be believed open (containing water) and somewhat wider than compressive/shear faults, which are orthogonal or inclined with respect to the direction of tectonic stress and therefore tend to be tighter (containing no or very less amount of water). Thus, it should be much easier to recognize tensional faults in satellite scene than shear faults and this should be reflected in the lineaments frequency histogram.

Sener et al. (2004) demonstrated the role of integration of GIS and remote sensing in groundwater investigation in Burdur, Turkey. They derived information about the geology, land use and lineament with the help of Landsat TM data composed of various analyses on the TM 7-4-1 band. In addition, contours, roads, creeks and springs were digitized from a topographic map of $1 / 100,000$ scale to produce a drainage density map. They produced groundwater potential map by integrating thematic maps such as maps representing annual rainfall, geology, land use, lineament density, slope, topography and drainage density. Thermal imagery describe long wave radiation emitted from the surface, used to examine temperature anomalies in water bodies, though it's more complex interpretation could be used in groundwater modeling. Sibliski and Okonkwo (2007) used airborne MSS, air borne thermal remote sensing and ground resistivity. The results from image analysis indicates that darker shades represent cooler, deeper water due to subsurface and underground cavities while lighter shades indicates surface or near surface warmer water along with sources of contamination, direction of flow of such contamination, the position of interceptive measures and the analysis of corresponding contamination. Remote sensing and geophysical techniques for differentiating fracture zones for well site location in
Lohardaga and Gumla distract of Bihar, India (Sinha et al. 1990). Mukherjee et al. (2007) used remote sensing and geophysical techniques for determining the facture zones for well site location in Aravali Quartzite, Delhi, India. They used IRS 1C LISSIII data and vertical electrical sounding (VES) techniques for groundwater prospect zoning in hard rock terrain. They conducted VES survey using Schlumberger electrode configuration to identify the detailed variations of groundwater prospect. The results of these studies show the emphasis of the integrated approaches of remote sensing with other geophysical techniques.

\section{Hyperspectral remote sensing in groundwater hydrology}

Hyperspectral sensors are the most advanced optical remote sensing systems which has capability of detecting and recording in more than hundreds narrow spectral bands across the visible and medium wavelength infrared portions of the spectrum (typically 0.4 to about $2.5 \mu \mathrm{m}$ ). This technology has been used globally in different fields to detect discharge of surface water pollution, map sensitive vegetation distribution and map the disturbance of natural drainage adjacent to canals, etc. Determination of discharge-recharge zones utilizing hydrologic models requires large volume of data from various sources. Integrated hyperspectral remotely sensed data and GIS could act as an effective tool in characterizing groundwater flow systems (Singh et al. 2013) and dischargerecharge relationships. Hyperspectral data is used to detect the subtle changes in vegetation, water, soil and mineral reflectance (Navalgund et al. 2007). Calculating soil water balance as a function of time requires various data in addition to average evapotranspiration (ET) and precipitation $(\mathrm{P})$ to account the water storage in the soil. A soil water balance model (SWBM) requires some data on field capacity of soil, which could be estimated based on soil type (Brunner et al. 2007a, b). Hyperspectral satellite information can aid (Ben-Dor et al. 2004; Brunner et al. 2007a, b) in the appropriate hydrologic modeling and management of groundwater.

However, hyperspectral remote sensing has enormous potential to extend satellite remote sensing beyond what has been possible with aerial photography and other broadband multispectral imagers. In the near future, it should be of great interest to the hydrologists, hydrogeologist/hydraulic engineers as a way to create timely and reliable information about groundwater resources. The current common limitation of hyperspectral remote sensing lies in the image processing because it provides enormous amount of data, which require different approaches and methodologies for processing and analysis. 


\section{Microwave remote sensing in groundwater hydrology}

A radar image interpretation is arduous in nature when compared with visual or near-infrared image because a radar image shows the backscatter signal of emitted pulses. The launch of SeaSat satellite in 1978, the first ever civilian spaceborne imaging radar instrument (SAR) has opened a new era to the utility of radar data to that track changes in Earth's oceans, land and ice (Winokur 2000). Estimating landscape surface roughness using radar helps in modeling of the land surface. Surface soil moisture data derived from passive microwave data provide information about the surface and subsurface processes along with the hydrologic fluctuations. The existence of cloud appears as the single most important breakage for optical remote sensing satellite to capture the image in bad weather conditions (Rashid et al. 1993). The development of microwave remote sensing, particularly radar imageries, solved the problem because the radar pulse can penetrate cloud cover. Various groundwater exploration and management projects incorporated both synthetic aperture radar (SAR) imagery and optical remote sensing imagery simultaneously in a single project (Chen et al. 1999). Radar remote sensing offers the capability to deal with problems pertaining to rainfall estimation (Uijlenhoet and Russchenberg 1996) and the utilization of microwave tomography (new imaging method based on contrast in dielectric properties of materials) as an alternative to weather radar measurement in limited areas (Giuli et al. 1996). Various researchers used the optical and SAR data as the basis for glaciological modeling and snow melt monitoring (Haefner et al. 1996). Apart from its all-weather capability, the most vital advantage of using SAR imagery lies in its ability to sharply distinguish boundary between land and water. Single broadband of electromagnetic spectrum has very confined capabilities in discriminating the process and spatial features present on the earth's surface (Teeuw 1995). Various scientific researches have identified and validated the importance of microwave satellite images for groundwater assessment, exploration, management and hydrologic modeling. Edet et al. (1998) used black and white radar imagery and aerial photographs to define hydrologic and hydro-geologic features in parts of the study area. The explicit results of the study showed the areas in the form of high, medium and low groundwater potential.

Subtle changes in land elevation may be precisely measured using interferometric synthetic aperture radar (InSAR). InSAR analysis includes the imaging of the same point from two viewing angles at different times (Becker 2006). Elevation changes can be calculated from the change in phase of the reflected signal (Galloway et al.
1998). The precession of elevation measurements will depend on the climatic region. In a very humid region, accuracy of measurement is in the order of $10 \mathrm{~cm}$ and in very dry regions, in the order of $1 \mathrm{~mm}$ (Galloway et al. 1998). The capability of InSAR has been illustrated in the study of groundwater storage changes in semi-arid regions such as Southern California (Galloway et al. 1998). The utility of InSAR is augmented through its combination with numerical models of groundwater withdrawals at the basin scale (Galloway et al. 1998). The strength of InSAR is that it offers greater spatial extent and resolution of land subsidence that can be achieved through ground-based measurements (Becker 2006).

\section{Errors in remote sensing}

Here in this review paper, the common errors and their types in remote sensing are briefly highlighted. For more details, readers are referred to consult the research paper written by (Lunetta et al. 1991).

1. Data acquisition error: Geometric aspects, sensor systems, platforms, ground control, scene consideration.

2. Data processing error: geometric rectification, data conversion.

3. Data analysis error: quantitative analysis, classification systems and data generalization.

4. Data conversion error: raster to vector and vector to raster.

5. Error assessment: sampling, spatial autocorrelation, error matrix, locational accuracy, discrete multivariate statistical techniques and reporting standards.

6. Final product presentation error: geometric (spatial) error, thematic (attribute) error.

\section{Uses of GIS in hydrological modeling}

In the past few years, the areas of researches based on GIS modeling have seen in elevated concern (Shamsi 2005). The use of GIS for simple two-dimensional modeling using standard overlay procedures is now widespread (Berry 1987). Extension to three-dimensional spatial and dynamic modeling is crucial for applications in many disciplines (e.g. groundwater, surface water, watershed management and modeling, climatology, marine science, geology and soil modeling) (Davis and Davis 1998; Ehlers et al. 1989). This approach involves programming the model with the available tools of GIS. Modeling within the GIS is effective for models like Universal Soil Loss Equation, DRSTIL, DRASTIC or TR55. These are mathematically and conceptually simple models, requiring least extent of

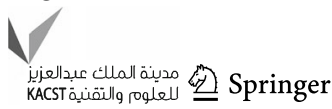


developer expertise. This approach also works well for home-grown models and for components of bigger data systems (DePinto et al. 1993). It is the easiest approach because the only software one needs to know is GIS. As GIS software has emerged to include more hydrologyspecific tools, this level of integration has increased in popularity.

\section{Data bridge}

Certainly, the most common approach to connecting models and GIS has been through data conversion. People have been really resourceful and creative in writing custom programs to pass spatial data from GIS to a model, later covert the results back to display and further examined in GIS, using models such as AGNPS, HEC-2, WASP4, SHE and many others.

\section{Embedded code}

This is the complex and tightest method of integration. It requires extreme programming resources and reduces the redundancy. Usually this includes embedding of the input/ output routines of the GIS into the model, permitting the model to read and write GIS data in its native format. The inadequacy of intermediate conversion steps develop an application with a speed that grants development of interactive applications which was not previously possible, with models such as SWMM and MODFLOW. Some developers have utilized the GUI tool kit of the GIS to develop turnkey applications that launch the model from within the GIS so that it is hidden from the user who simply communicates through a menu. While great for the end user, this type of interface can be a nightmare for the developer to develop and maintain.

\section{Linkage issues}

Even though the methods of integration change, the issues approximately remain the same. Complex calculations like differential equations or series approximations could be done with the help of model. If the mathematics is within the realm of GIS, the modeling within the GIS can be considered doing. Some models can be conveniently canned into an intuitive graphic user interface (GUI), but for a model with a complex interface, or one that is easily accepted like AGNPS, it is apparently best to help the model understand data from GIS. Some models receive regular or significant updates, which can be tough to ahieve if the model is embedded inside a large application. Some models may be needed by law, or have legal implications, that could be nullified by an unauthorized developer making adjustments to the model. Additional discussions of methods and considerations for linking models and GIS can be found in Maidment (1993) and Fedra (1993).

\section{Problems}

According to Howari et al. (2007), there are three types of common problems: the existing problems, inherited problems and the computational problems. The hydraulic model usually has the capacity to analyze, predict and solve engineering problems without taking into consideration the geographical prospective (McKinney and Cai 2002). Under these circumstances, GIS becomes a valuable tool (Pullar and Springer 2000). It is noteworthy that there are strong grounds for believing that GIS has an important function to play since groundwater is the multi-dimensional aspect which has a spatial component. Furthermore, for the past two decades, many GIS integrated modeling applications have capitalized GIS as database manager and visualization tool (Westervelt and Shapiro 2000). Moreover, once data are available in GIS, it can be extracted, combined with other data, reformatted as necessary for various modeling processes and even used to generate other inputs needed by the models (Robbins and Phipps 1996).

Djokic et al. (1994) developed a tight coupling procedure, namely ARC/HEC-2, which exports the terrain data from Arc/info into HEC-2 and converts HEC-2 water surface elevations into GIS coverage in Arc/info. Evans (1998) created avenue scripts to import cross-section location as $\mathrm{XYZ}$ coordinates from terrain models to develop channel and reach geometry to be used in HECRAS calculations. Upon completion of the calculation, GIS was used to visualize the results. In 1998, ESRI, a leading GIS software provider enhanced Evan's (1998) codes and created AVRAS which is a more user-friendly feature. The latest version of AVRAS is HEC-GeoRAS 3.1.1.

According to Sui and Maggio (1999), GIS functionalities embedded in the hydrological modeling packages were primarily adopted by hydrologic developers. This approach has and advantage in terms of maximum freedom for the system design. This approach provides the ability to incorporate the latest development in hydrological modeling. The problem in this approach lies in the form of data management and visualization. The developers of the latest version of RiverCAD, HEC-HMS 2.0, RiverTools, MODFLOW and SUTRA have basically taken these approaches (Djokic et al., 1995). On the other hand, GIS software developers in recent years have made extra efforts to upgrade the analytical and modeling capabilities of their products. Hellweger and Maidment (1999) accomplished a vital lead in the integration of hydrologic models and GIS, with the advancement of a GIS-based tool, named HECPREPRO. The tool includes the compilation of Arc/Info Language scripts (AMLs) utilized to pre-process and 
export spatial data to HEC-HMS, a broadly used hydrologic package with various options for simulating rainfallrunoff processes. Research and development of the tools for watershed hydrology are continuing to improve land form descriptions, surface interpolation and flow routing algorithms (Moore et al. 1993). GIS has also included tools to solve two-dimensional groundwater flow problems. These tools allow the generation of a particle tracking, Darcian flow field and Gaussian dispersion (Tauxe 1994). They show assuring advancement in the quick assessment of local, large-scale groundwater problems and in illustrating capture zones for wellhead protection.

\section{Existing problems}

GIS has supported hydrologist and hydraulic engineers with the ideal computing platform for data inventory, mapping, parameter extraction, visualization, surface modeling and interface development for hydrological modeling, thus enormously facilitating the design, calibration and implementation of several hydrologic and hydraulic models (Lanza et al. 1997; Su and Troch 2003). The technical hurdles related to the database integration are well documented (Adam and Gangopadhyay 1997). Very fewer papers in the literature have discussed the broad conceptual issues involved in the integration of GIS with hydrological modeling. Many problems in both hydrological models and the current generation of GIS are usually noticed. These problems must require to be addressed before we can make the integration of GIS with hydrological modeling theoretically consistent, scientifically rigorous and technologically interoperable (Lanza et al. 1997; Su and Troch 2003).

\section{Inherited problems}

According to Chow et al. (1988), hydrological models could possibly be classified according to the conceptualization and assumptions of three key parameters: randomness, space and time. In current practices, deterministic lumped models are dominated in GIS-based hydrological modeling. There is the availability of various deterministic lumped modeling packages such as the US Army Corps of Engineers HEC-RAS and HEC-HMS, the US Soil and Conservation Service's TR-20 and TR-40, USDA's SWAT, DoT WSPRO, EPA's WASP and BASINS and USGS's DRM3 and PRMS, etc. (Singh and Frevert 2002a, b). The future of these deterministic models has been challenged by various researches (Grayson et al. 1992; Smith and Goodrich 1996) and many researchers have been active in developing spatially distributed and stochastic models (Beven and Moore 1992; Romanowicz et al. 1993).
Nevertheless, these newly developed models are widely used in practice.

\section{Computational problem}

The development of GIS till date has depended upon a limited map metaphor (Burrough and Farnk 1995). The majority of GIS databases are presently represented in vector format, which is appropriate due to storage efficiency but difficult to manipulate analytically (Howari et al. 2007). The process of vectorization or rasterization has peculiar errors that manifest as representational errors in a given GIS system (Howari et al. 2007). As a consequence, the representation schemes and analytical functionalities in GIS are equipped to map layers and geometric transformations. The layer approach inevitably forces a segmentation of geographic features (Raper and Livingstone 1995). This representation scheme is not only temporarily fixed but is also incapable of handling overlapping aspect (Hazelton et al. 1992).

Hence, to complete the seamless integration of GIS and hydrological models, more studies are required at higher level to create and incorporate novel approaches to conceptualize space and time that are interoperable together within GIS and hydrological models (Su and Troch 2003). Certainly, the current practices of integrating GIS and hydrological modeling are essentially technical in nature and have not touched more fundamental aspects in either of hydrological modeling or GIS (Howari et al. 2007). Simply being able to run a HEC-RAS or HEC-HMS model in Arc Info or a CAD system improves neither the theoretical foundation nor the performance of the model. GIS-based hydrological modeling has resulted in tremendous representational compromise (Gan et al. 1997). Tackling such problem paves the way for a fresh look at the integration of GIS with hydrological modeling.

\section{Issues}

Some of the common modeling concerns that are to be managed as described by Noman et al. (2001) are the following:

1. Data structure of the digital terrain model (DTM).

2. Hydraulic model integration.

3. Flood plain delineation.

4. Accuracy of inundation maps.

5. Acceptability, flexibility and expandability and uncertainties.

Numerous modeling techniques to integrate environmental models with GIS have been discussed and analyzed earlier by many researchers to find an optimum 
combination of various methods (Alaghmand et al. 2008). These involve individual pixel analysis to process model, remote and in situ sensing, data assimilation and state space estimation algorithms. In the present scenario, there are some general problems in hydrological research on passing information from point information to regionally distributed information. The correlations between ground measurements and remote sensing data are subjected to noise during collection, processing and analysis. Such stochastic relationships can, however, be used in the conditioning of stochastic models and data assimilation. Earth observation from airborne or space borne platform is the ideal observational approach capable of providing data at the relevant scales and resolution required to extrapolate findings of in situ (field) studies to larger areas, to document the heterogeneity of the landscape at the regional scale and to connect these findings into a global view (Schaepman 2006). Extrapolation can either be accomplished by statistical and/or GIS techniques (Guisan and Zimmermann 2000), as well as by process modeling of extended and complex system. Usually, only less number of point measurements are available, although groundwater models need spatial and temporal distributions of input and calibration data. If such specific data are not available, models cannot play auxiliary role in decision making, as they are particularly undermined and uncertain. Current advancement in remote sensing has opened new sources of spatially distributed data. As the relevant entities such as heads or transmissivities, water fluxes, etc, cannot be measured directly by remote sensing, ways have to be discovered to connect the measured quantities as input data needed by the model (Brunner et al. 2007a, b). Regional hydrological models needs distributed input data. Classical hydrological measurements provide only point data, for example at a weather station, a gauging station or a borehole. In principle, the patterns from remote sensing can be translated to a deterministic distribution of input data on a cell-by-cell basis or in the form of zones. Even if absolute values of these data are uncertain, they still curtail the degree of freedom of the model and thus lead to a betterposed inverse problem and a robust solution. The integration of geographic information system (GIS) with distributed parameter hydrologic model is playing a raising role in designing, calibrating, modifying and comparing these models. Successful application of GIS technology in hydrologic modeling needs careful planning and extensive data manipulation. Three primary tasks identified in most hydrologic applications with sophisticated computerized numerical models are the spatial database construction, integration of spatial model layers and the GIS and model interface. The first task is generally time-consuming, but is becoming more justifiable with the ever-increasing volume of data available from many organizations. The second task can be generalized in a series of spatial overlaying and/or projecting procedures that yield the final modeling layer. This task is becoming less tedious with the rapid advancement of sophisticated GIS capabilities. The last task may require actual programming with complication varying from case to case. This article is both an introductory overview to GIS applications in hydrologic modeling and a review of what has been achieved in this rapidly growing field (Zhang et al. 1990). In the recent years, there has been increasing interest in the issue of scale in remote sensing (Dungan et al. 2002). With the aid of remote sensing and GIS, it is easier to predict changes in ungauged basins, perform modeling base on the data, etc. The hydrologic modeling utilize variety of models such as simple linear model to process-based model, also known as deterministic model which can be divided into single-event models and continuous simulation models. The more complex and realistic models are stochastic models, which have different conceptualization and assumption of randomness, space and time (Sui and Maggio 1999) in comparison to deterministic models. Stochastic models deals differently with uncertainties.

Wilson and Gallant (2000) have described issues concerning "scale" and they referred to the level of details at which information can be observed, represented, analyzed and communicated. Various researchers attempting to model hydrological processes at the scale of drainage basin have found difficulties extracting, synthesizing and aggregating data from limited number of locations (Stuart and Stocks 1993; Singh et al. 2013) and finding the suitable data for fully distributed models such as Institute of Hydrology Distributed Model (IHDM) or the Systeme Hydrologique European (SHE). These models operate in finer spatial resolution. For appropriate functioning, these models require many parameter values that are difficult to measure in the field which has limited their usefulness for practical purposes (Bathurst 1988; Stuart and Stocks 1993).

\section{Models of integration and their need}

Groundwater aquifer is a complex natural system which requires knowledge and expertise from different fields. In this era of unprecedented data proliferation, the close integration of remote sensing, GPS and GIS has expected greater importance for handling of disparate, yet intrinsically complimentary spatial data (Mesev 1997). Integration is necessary to equip the users with information in more significant way (Ehlers et al. 1991). According to Mesev (1997), the best RS-GPS-GIS integration can facilitate extended inventories, rapid database update, greater analytical flexibility and broader potential applications. Nevertheless, the worst site of RS-GPS-GIS integration may 
cause redundancy, analytical complexity, compounded errors (additive and multiplicative errors) and unfocussed objectives. Remote sensing techniques have ability to offer data acquisitions and digital analysis. These techniques, in recent times, provide data ranging from 100s of meters to centimeter in resolution. GPS is also a satellite-based platform utilized for identification of exact location, velocity and time, yet it is mostly used for identification of earth's coordinates. GIS distinguishes itself from other two technologies in that it enables data from multi-sources to be collected, integrated, analyzed, retrieved and even modeled owing to its powerful analytical functionality (Gao 2002). GIS functionality cannot be fully met and realized without the fidelity in database.

According to Gao (2002), these geospatial technologies are independent of one another in their basic functions. But these technologies are fundamentally complimentary in their secondary functions. When these technologies are implemented individually, they could work properly in certain cases, but functionality of these technologies can only be fully realized through their integration to manage the natural resources. Integration not only promotes their wide ranging applications in resource management and monitoring (Thakur et al. 2011), but also widens the scope to which they are applicable (Gao 2002). According to Gao (2002), the integration of these technologies in combination with ground monitoring systems has confirmed to be an efficient method for collecting, managing, analyzing, modeling and presenting output of spatial data for local, regional and global water resources development and management (Chen et al. 1997).

Numerous researches have done useful work on integration of RS-GPS-GIS in their studies to map, identify and explore recharging sites, drilling sites, well sitting sites and others. But, maximal researches have not focused and discussed the types of models used for the integration and level, at which they were used for the integration of RSGPS-GIS. Nevertheless, in situations such as to meeting the increasing demand of fresh water supply, inventory of potential recharge sites, groundwater pollution, impact of urbanization and industrialization on groundwater studies, closer and deeper look on the types of models of integration and levels of integration is needed.

\section{Examples of integration in practices}

According to Gao (2002), there are various diverse methods for the integration of remote sensing, GIS and GPS. He conceptualized and summarized these methods into four models: linear model (LM), interactive model (IM), hierarchical model (HM) and complex model (CM). The adopted flow charts are shown below (Figs. 1, 2, 3, 4). The details can be found in Gao (2002).

Various researchers have used the concept of RS-GPSGIS integration in linear model in the field of groundwater sitting sites, exploration, mapping lineaments, point pollution source, potential recharge sites and others. Interactive model has mostly been used by the agriculture scientists for the estimating the crop yield. However, very few scientific studies have focused on the discussion about the type of integration.

\section{Integrating GIS with hydrologic model}

The capability to implement model in a GIS environment has anticipated rise in the number of models, generally used to predict soil loss, sediment yield, nutrient loss, pollutant transport in watershed and groundwater movement. Some of these models are AGNPS (agricultural non point source), SWAT (soil and water assessment tool), ANSWERS (aerial non point source watershed response simulation) and HSPF (hydrologic simulation programfortran). The integrated use of GIS and prediction models can be considered a powerful instrument to support decision makers in identifying areas at risk of pesticide contamination. The integration of models with GIS has a
Fig. 1 The linear model of integration (Source: Gao 2002)

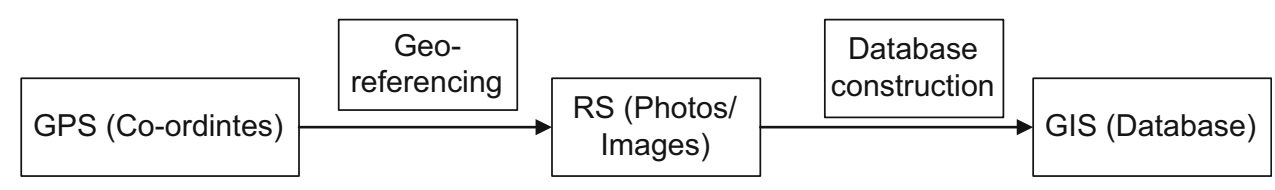

Fig. 2 The interactive model of integration (Source: Gao 2002)

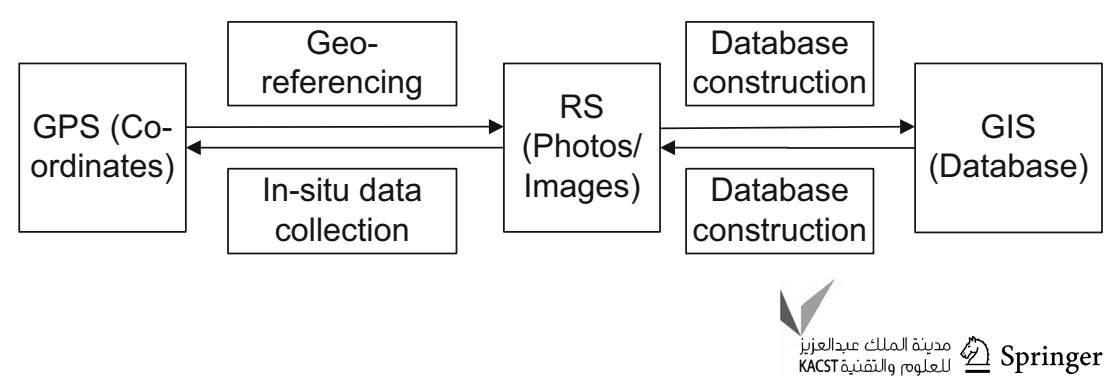


Fig. 3 The hierarchical model of integration (Source: Gao 2002)

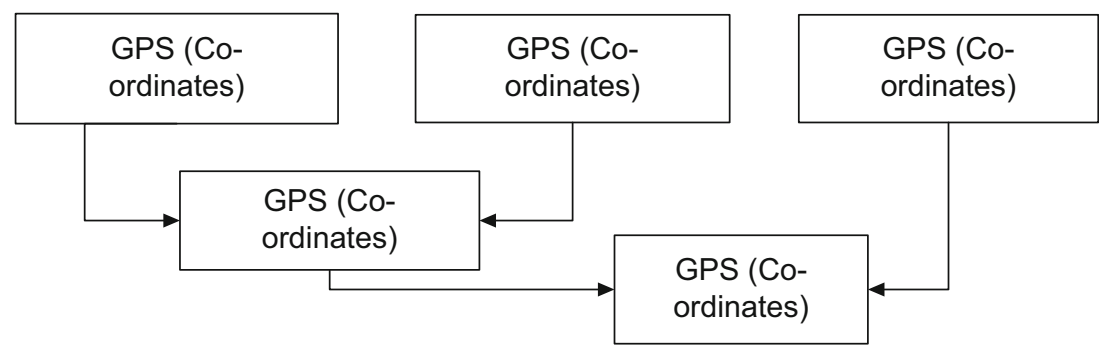

Fig. 4 The complex model of integration (Source: Gao 2002)

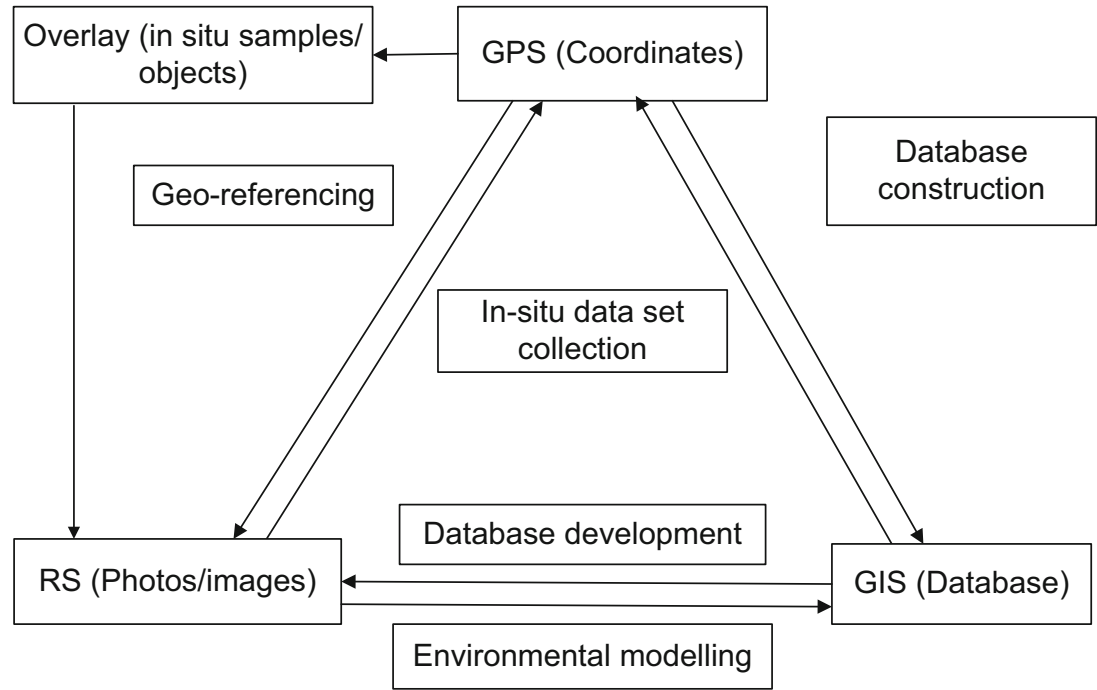

number of benefits including short running time and quick production of results. WebGIS has been used for integration and visualization of hydrological data in the model (UIZ 2015).

\section{Methods of integration of GIS with hydrological modeling}

According to Kopp (1996), three general approaches exist to GIS model integration with hydrological modeling, namely GIS-based modeling, Data Bridge and embedded code. The integration methods are constantly developing but still the general approaches and issues remains the same. Figure 5 demonstrates the methods of GIS integration with hydrological modeling.

\section{Conclusion}

Water, a vital natural and a potential resource necessary for all forms of lives, is itself in a great danger in terms of degrading quality and diminishing quantity. The integration of $3 \mathrm{~S}$ tools and techniques works as a central concept in water resource management. However, when a question arises on whether the management has to be integrated, then the answer should be yes. Integration of any known scientific technology leads to better, improved understandings and helps different streams of peoples to solve the known as well as to predict the emerging new problems. Various researches have dealt with problems relevant to water such as waterborne diseases, sewage pollution, effluent and salt-water intrusion (Thakur et al. 2012). This paper gives an insight to the researchers working in the field of geospatial application in water resource.

In various developing countries, many GIS applications are still being used as advanced digital cartographic systems oriented towards the maintenance of digital geographic data (Densham 1991) and relatively inferior with respect to high-level analysis and modeling abilities that are necessary for sustainable management of resources. The development and assessment of topographic and hydrologic database that extend over large areas are the areas of active research. The future of distributed mobile GIS (DM GIS) will be invaluable for applications in the fields such as emergency water supply, groundwater pollution, scientific field studies, environmental monitoring and planning (Karimi et al. 2000; Gao 2002). The most challenging issue for the efficient implementation of DM 
Fig. 5 Integrating GIS with Hydrological modeling: current practices (Source: Sui and Maggio 1999)

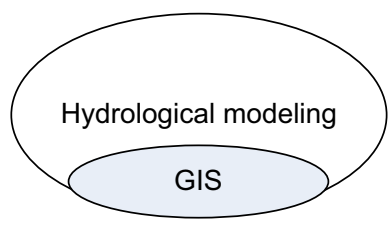

A Embedding GIS in hydrological modeling

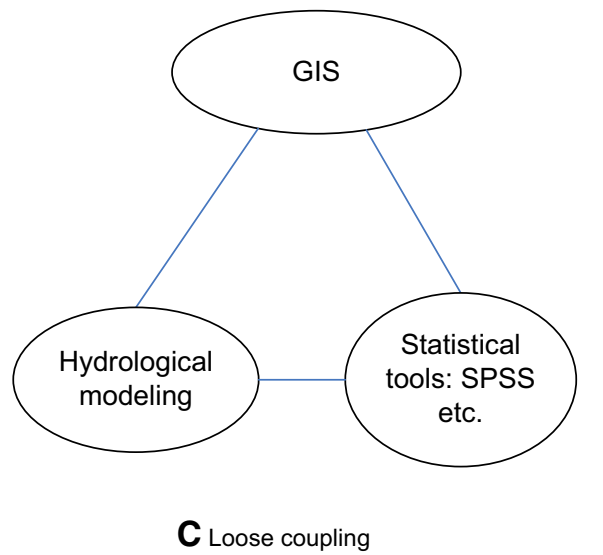

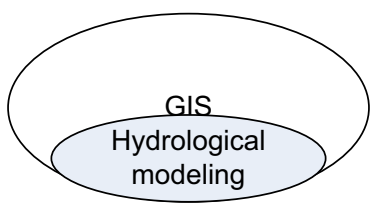

B Embedding GIS in hydrological modeling

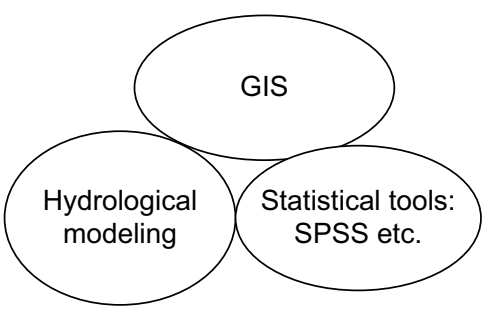

D Tight coupling
GIS is the inspection of mathematical relationships among the spatial objects (e.g. topology) for the data in the database and reconciliation of topological inconsistencies when they occur (Gao 2002).

Acknowledgments The authors would like to acknowledge K. Banerjee Centre of Atmospheric and Ocean Studies, IIDS, University of Allahabad, Allahabad (U.P.), India for support and provision of important information. They are duly thankful to the team of Health and Environmental Management Society (HEMS) Nepal for their continuous guidance and valuable suggestions.

\section{Compliance with ethical standards}

Conflict of interest The authors declare no conflict of interest.

Open Access This article is distributed under the terms of the Creative Commons Attribution 4.0 International License (http:// creativecommons.org/licenses/by/4.0/), which permits unrestricted use, distribution, and reproduction in any medium, provided you give appropriate credit to the original author(s) and the source, provide a link to the Creative Commons license, and indicate if changes were made.

\section{References}

Adam NR, Gangopadhyay A (1997) Database issues in geographic information systems. Kluwer Academic Publishers, Boston

Alaghmand S, Abustan I, Mohammadi A. A literature review of applications of geography information system (GIS) in river hydraulic modeling. ICCBT 2008-D, 04, 37-48

Arnold JG, Allen PM, Bernhardt GA (1993) Comprehensive surfacegroundwater flow model. J Hydrol 142:47-69
Barrett EC, Kidd C (1987) The use of SMMR data in support of a VIR/IR satellite rainfall monitoring technique in highly contrasting climatic environments. In: Fischer JC (ed) passive microwave observing from environmental satellites, a status report. NOAA Tech. Rep. NESDIS 35, Washington, DC, pp 109-123

Bathurst JC (1988) Physically based distributed modeling of an upland catchment using the Systeme Hydrologique European. J. Hydrology 87:79-102

Becker MW (2006) Potential for satellite remote sensing of groundwater. Ground Water 44:306-318

Ben-Dor E, Goldshleger N, Braun O, Kindel B, Goetz AFH, Bonfil MN, Binaymini Y, Karnieli A, Agassi M (2004) Monitoring infiltration rates in semi-arid soils using airborne hyperspectral technology. Int J Remote Sens 25:2607-2624

Berry JK (1987) Fundamental operations in computer assisted map analysis. Int J Geogr Sys 1:119-136

Beven KJ, Moore I (1992) Terrain analysis and distributed modeling in hydrology. Wiley \& Sons, Chichester

Bhasker NR, Wesely PJ, Devulapalli RS (1992) Hydrologic parameter estimation using geographic information systems. J Water Res Plan Manage 118:492-512

Blumberg DG (1998) Remote sensing of desert dune forms by polarimetric synthetic aperture radar (SAR). Remote Sens Environ 65:204-216

Brunner P, Li HT, Li WP, Kinzelbach W (2007a) Generating soil electrical conductivity maps at regional level by integrating measurements on the ground and remote sensing data. Int $\mathbf{J}$ Remote Sens 28:3341

Brunner P, Franssen HJH, Kgothang L, Gottwein BP, Kinzelbach W (2007b) How can remote sensing contribute in groundwater modeling. Hydrogeol J 15:5-18

Case JB (1989) Special GPS issue. Photogramm Eng Remote Sens 55:1723-1754

Chen P, Liew SC, Lim H (1999) Flood detection using multitemporal Radarsat and ERS SAR data. In Proc. 20th Asian Conference of Remote Sensing, Hong Kong 
Chow VT, Maidment D, Mays L (1988) Applied hydrology. McGraw-Hill, New York

Dabbagh AE, Al-Hinai KG, Khan MA (1997) Detection of sandcovered geologic features in the Arabian Peninsula using SIR-C/ X-SAR data. Remote Sens Environ 59:375-382

Das D (1994) Environmental appraisal for water resource development. International conference on Disaster Management (ICODIM). Tejpur University, Tezpur

Davis BE, Davis PE (1998) Marine GIS: concepts and considerations. In: Proceedings of the GIS/LIS Conference, San Antonio

Densham PJ (1991) Spatial decision support systems. In: Maguire DJ, Goodchild MF, Rhind DW (eds) Geographical information systems: principles on applications, vol vol 1. Longman, London, pp 403-412

DePinto JV, Atkinson JF, Calkins HW, Densham PJ, Guan W, Lin H, Xia F, Rodgers PW, Slawecki T, Richardson WL (1993) Development of GEO-WAMS: a watershed modeling support system for integrating GIS with watershed analysis models. In Prelim. Proc. Second Int. Conf./Workshop on Integrating Geographic Information Systems and Environmental Modeling, Breckenridge, Colorado

Djokic D, Beavers MA, Deshakulakarni K (1994) ARC/HEC2: an ARC/INFO- HEC-2 Interface. In Proceedings of the 21st Annual Conference on Water Policy and Management, American Water Resources Association, ASCE

Djokic D, Coates A, Ball JE (1995) GIS as integration tool for hydrologic modeling: a need for generic hydrologic data exchange format. In ESRI User Conference, Redlords

Dungan JL, Perry JN, Dale MRT, Legendre P, Citron-Pousty S, Fortin MJ (2002) A balanced view of scale in spatial statistical analysis. Ecography 25:626-640

Dutartre P, Goachet E, Pointet T (1990a) Implantation de forages d'eau en miliex fissurés. Une approache intégrée de la télédétection et de la géologie structurale en Nouvelle Caledonie. Hydrogéologie 2:113-117

Dutartre P, King C, Pointet T (1990b) Utilisation de l'image SPOT en prospection hydrogéologique au Burkina Faso. Hydrogéologie 2:145-154

Edet AE, Okereke CS, Teme SC, Esu EO (1998) Application of Remote sensing data to groundwater exploration: a case study of the crossriver state, Southeastern Nigeria. Hydrogeol J 6:394-404

Ehlers M, Edwards G, Bedard Y (1989) Integration of remote sensing with geographic information systems: a necessary evolution. Photogramm Eng Remote Sens 55:1619-1627

Ehlers M, Greenlee D, Smith T, Star J (1991) Integration of remote sensing and GIS: data and data access. Photogramm Eng Remote Sens 57:669-675

Engman ET, Gurney RJ (1991) Remote sensing in hydrology. Chapman and Hall, London

Evans TA (1998) GIS Data exchange for the hydrologic engineering center's hydraulic and hydrologic models. In Proceedings of International Water Resources Engineering Conference, ASCE

Fedra K (1993) Distributed models and embedded GIS: strategies and case studies of integration models. In Prelim. Proceeding Second International Conference/Workshop on Integrating Geographic Information Systems and Environmental Modeling, Breckenridge, Colorado

Fortin JP, Bernier M (1991) Processing of remotely sensed data to derive useful input data for the HYDROTEL hydrological model. In: Putkonen J (ed) Remote sensing: global monitoring for earth management, Proceedings of international geoscience and remote sensing symposium, Helsinki University of Technology, Espoo, Finland, IEEE, New York

Gahegan M, Flack J (1999) The integration of science understanding within a geographic information system: a prototype approach for agriculture applications. Trans GIS 3:31-50
Galloway DL, Hudnut KW, Ingebritsen SE, Phillips SP, Peltzer G, Rogez F, Rosen PA (1998) Detection of aquifer system compaction and land subsidence using interferometric synthetic aperture radar. Antelope Valley, Mojave Desert, California. Water Resour Res 34:2565-2573

Gan TY, Dlamini EM, Biftu GF (1997) Effects of model complexity and structure, data quality, and objective functions on hydrologic modeling. J Hydrol 192:81-92

Gao J (2002) Integration of GPS with remote sensing and GIS: reality and Prospect. Photogramm Eng Remote Sens 68:447-453

Gossel W, Ebraheem AM, Wyeisk P (2004) A very large-scale GIS based groundwater flow model for Nubian sandstone aquifer in Eastern Sahara (Egypt, northern Sudan and Eastern Libya). Hydrogeol J 12:698-713

Grayson RB, Moore ID, McMahon T (1992) Physically based hydrologic modeling, is this concept realistic? Water Resour Res 28:265-279

Guisan A, Zimmermann NE (2000) Predictive habitat distribution models in ecology. Ecol Model 135:147-186

Haefner H, Seidel K, Ehrler C (1996) Application of snow cover mapping in high mountain regions. Phys Chem Earth 22:275-278

Hazelton NWJ, Leahy FJ, Williamson IP (1992) Integrating dynamic modeling with geo-graphic information systems. J Urban Reg Inf Sys 4:47-58

Hellweger EL, Maidment DR (1999) Definition and connection of hydrologic elements using geographic data. J Hydraul Eng 4:10-18

Howari MF, Sherif MM, Singh PV, Al Asam SM (2007) Application of GIS and remote sensing techniques in identification, assessment and development of groundwater resources. In: Thangarajan M (ed) Groundwater resource evaluation, augmentation, contamination, restoration, modeling and management. Springer, Netherlands, pp 1-25

Humes KS, Kustas WP, Moran MS (1994) Use of remote sensing and reference site measurements to estimate instantaneous surface energy balance components over a semiarid rangeland watershed. Water Resour Res 30:1363-1373

Jha MK, Chowdhury A, Chowdary VM, Peiffer S (2007) Groundwater management and development by integrated remote sensing and geographic information systems: prospects and constraints. Water Resour Manage 21:427-467

Kaufman H, Reichart B, Hotzl, H (1986) Hydrogeological research in Peloponnesus karst area by support and completion of Landsat thematic data. In: Proceedings of the IGARSS 86 Symposium, Zurich

Karimi HA, Krishnamurthy P, Banerjee S, Chrysanthis PK (2000) Distributed mobile GIS: challenges and architeture for integaration of GIS, GPS, mobile computing and wireless communications. Geomatics Info Magazine 14:80-83

Kopp MS (1996) Linking GIS and hydrological models: where we have been, where we are going? In: Kovar K, Nachmebel HP (eds) Application of geographic information systems in hydrology and water resources management, Proceedings of the HydroGIS 96 Conference, IAHS Publ., Vienna

Lakhtakia MN, Miller DA, White RA, Smith CB (1993) GIS as an integrative tool in climate and hydrology modeling models. In Prelim. Proc. Second Int. Conf./Workshop on Integrating Geographic Information Systems and Environmental Modeling, Breckenridge, Colorado

Lanza LG, Schultz GA, Barrett EC (1997) Remote sensing in hydrology: some downscaling and uncertainty issues. Phys Chem Earth 22:215-219

Lim KJ, Engel B, Kim Y, Bhaduri B, Harbor J (1999) Development of the Long-term Hydrologic Impact Assessment (L-THIA) WWW Systems (St. American Society of Agricultural Engineers Paper No, Joseph, p 992009 
Loague KM (1988) Impact of rainfall and soil hydraulic property information on runoff predictions at the hill slope scale. Water Res Res 24:1501-1510

Loague KM, Freeze RA (1985) A comparison of rainfall-runoff modeling techniques on small upland catchments. Water Res Res 21:229-248

Lunetta SR, Congalton GR, Fenstermaker KL, Jensen RJ, McGwrie CK, Tinney RL (1991) Remote sensing and geographic information system data integration: error sources and research issues. Photogramm Eng Remote Sens 57:677-687

Maidment DR (1993) GIS and hydrological modeling. In: Goodchild MF, Steyaert LT, Parks BO (eds) Environmental modeling with GIS. Oxford University Press, New York, pp 147-167

McKinney DC, Cai X (2002) Linking GIS and water resources management models: an object-oriented method. Environ Model Softw 17:413-425

Mesev V (1997) Remote sensing of urban systems: hierarchical integration with GIS. Comput Environ Urban Sys 21:175-187

Milzow C, Kgotlhang L, Kinzelbach W, Meier P, Bauer-Gottwein P (2008) The role of remote sensing in hydrological modeling of the Okavango Delta Botswana. J Environ Manage 90:2252-2260

Moore ID, Lewis A, Gallant JC (1993) Terrain Attributes: Estimation Methods and Scale Effects. In: Jakeman AJ, Beck MB, McAleer MJ (eds) Modeling change in environmental systems. John Wiley and Sons, New York, pp 189-214

Mukherjee S, Sashtri S, Gupta M, Pant KM, Singh C, Singh KS, Srivastva KP, Sharma KK (2007) Integrated water resource management using remote sensing and geophysical techniques: Arvali Quartzite Delhi, India. J Environ Hydrol 15:1-10

Navalgund RR, Jayaraman V, Roy PS (2007) Remote sensing applications: an overview. Curr Sci 93:1747-1766

Noman N, Nelson E, Zundel A (2001) Review of automated floodplain delineation from digital terrain models. J Water Resour Plann Manage 127(6):394-402

Orzol LL and McGrath TSS (1992) Modifications to the U.S. Geological Survey modular finite-difference ground water flow model to read and write geographic information system Files. United States Geological Survey Open File report No. 92-50, Portland

Pullar D, Springer D (2000) Towards integrating GIS and catchment models. Environ Model Softw 15:451-459

Raper J, Livingstone D (1995) Development of a geomorphological spatial model-using object oriented design. Int J Geogr Infor Sys 9:359-383

Robbins C and Phipps SP (1996) GIS/Water resources tools for performing floodplain management modeling analysis. In: Proceedings of AWRA (American Water Resources Association) Symposium on GIS and Water Resources, Fort Lauderdale

Romanowicz R, Beven K, Moore R (1993) GIS and distributed hydrological models. In: Mather PM (ed) Geographical information handling-research and applications. Wiley \& Sons, Chichester, pp 131-144

Running SW, Justice CO, Salomonson V, Hall D, Barker J, Kaufman YJ, Strahler AH, Huete AR, Muller JP, Vandebilt V, Wan ZM, Teillet P, Carneggie D (1994) Terrestrial remote sensing science and algorithms planned for EOS/MODIS. Int J Remote Sens 15:3587-3620

Sander P, Chesley MM, Minor TB (1996) Groundwater assessment using remote sensing and GIS in a rural groundwater project in Ghana, lessons learned. Hydrogeol J 4:40-49

Schaepman SG, Schaepman ME, Painter TH, Danzel S, Martonchik JV (2006) Reflectance quantities in optical remote sensingdefinitions and case studies. Remote Sens Environ 103:27-42

Sener E, Dayraz A, Ozcelik M (2004) An integration of GIS and remote sensing in groundwater investigations: a case study in Burdur, Turkey. Hydrogeol J 13:826-834
Shamsi UM (2005) Gis applications for water, wastewater, and storm water systems. CRC Press, USA

Shultz GA (1994) Meso scale modeling of runoff and water balances using remote sensing and other GIS data. Hydrol Sci J $39: 121-142$

Sibliski UE, Okonkwo JO (2007) Application of remote and ground sensing studies in the development of a typical groundwatermonitoring programme. Int J Environ Stud 64:207-220

Singh VP, Frevert DK (2002a) Mathematical models of small watershed hydrology and applications. Water Resources Publications, Highlands Ranch

Singh VP, Frevert DK (2002b) Mathematical Models of Large Watershed Hydrology. Water Resources Publications, Highlands Ranch

Singh P, Thakur JK, Singh UC (2013) Morphometric analysis of Morar River Basin, MadhyaPradesh, India, using remote sensing and GIS techniques. Environ earth sci 68(7):1967-1977

Sinha BK, Kumar A, Shrivastava D, Srivastava S (1990) Integrated approach for demarcating the fracture zone for well site location: a case study near Gumla and Lohardaga, Bihar. J Indian Soc Remote Sens 18:1-8

Smith LC (1997) Satellite remote sensing of river inundation area, stage and discharge: a review. Hydrol Process 11:1427-1439

Smith RE, Goodrich DC (1996) Investigating prediction capability of HEC-1 and KINEROS kinematic wave runoff models-Comment. J Hydrol 179:391-393

Srinivasan R, Arnold JG (1994) Integration of a Basin scale water quality model with GIS. Water Resour Bull 30:453-462

Stuart N and Stocks C (1993) Hydrological modeling within GIS: an integrated approach. In: Application of geographic information systems in hydrology and water resources, Proceedings of the HydroGIS 93 Conference, IAHS Publ., Vienna

Su ZB, Troch PA (2003) Applications of quantitative remote sensing to hydrology. Phys Chem Earth 28:1-2

Sui DZ, Maggio RC (1999) Integrating GIS with hydrological modeling: practices, problems and prospects. Compu Environ Urban Sys 23:33-51

Tauxe JD (1994) Porous media advection-dispersion modeling in a geographic information system; Center for Research in Water Resources, Bureau of Engineering Research, Univ. of Texas at Austin, Austin, Texas, Technical Report no. 253, 1994

Teeuw RM (1995) Groundwater exploration using remote sensing and a low cost geographical information. Hydrogeol J 3:21-30

Teme SC, Oni SF (1991) Detection of groundwater flow in fractured media through remote sensing techniques-Some Nigerian cases. J Afr Earth Sci 12:461-466

Thakur JK, Srivastava PK, Pratihast AK, Singh SK (2011) Estimation of evapotranspirationfrom wetlands using geospatial and hydrometeorological data. In: Geospatial Techniques for ManagingEnvironmental Resources. Springer, Netherlands, pp. 53-67

Thakur JK, Srivastava PK, Singh SK (2012) Ecological monitoring of wetlands in semi-aridregion of Konya closed Basin, Turkey. Reg Environ Change 12(1):133-144

Todd DK (1980) Groundwater hydrology, vol 2nd. Wiley \& Sons, New York, pp 363-364

Travaglia C, Dainelli N (2003) Groundwater search by remote sensing: a methodologicalapproach. Environ Nat Resour. Working Paper (FAO)

UIZ (2015) Environmental monitoring, analysis and interactive visualization-Emaiv, UIZ Umwelt und Informationstechnologie Zentrum. http://uizentrum.de/en/environmental-monitoringanalysis-and-interactive-visualization-emaiv. Accessed 15 Dec 2015

Watkins DW, McKinney DC, Maidment DR, Lin MD (1996) Use of geographic information systems in groundwater flow modeling. J Water Res Plan Manage ASCE 122:88-96 
Westervelt J and Shapiro M (2000) Combining scientific models into management models. In: 4th International Conference on Integrating GIS and Environmental Modeling, (GIS/EM4) Banff, Canada

Wilkinson GG (1996) A review of current issues in the integration of GIS and remote sensing. Int J Geogr Infor Sys 10:85-101

Wilson JP, Gallant JC (2000) Terrain analysis: principles and applications. Wiley, New York
Winokur RS (2000) SAR symposium keynote address. Johns Hopkins APL Technical Digest 21:5-11

Zhang H, Haan CT, Nofziger DL (1990) Hydrologic modeling with GIS: overview. Appl Eng Agri ASAE 6:453-458 